\title{
Insulin Management of Patients with Inadequately Controlled Type 2 Diabetes Admitted to Hospital: Titration Patterns and Frequency of Hypoglycemia as Results of a Prospective Observational Study (Hospital Study)
}

Jan Brož (D) · Denisa Janíčková Žd'árská · Jana Urbanová · Pavlína Pit'hová · Viera Doničová · Sabina Pálová · Barbora Pelechová · Anna Smržová · Milan Kvapil

Received: November 17, 2020 / Accepted: May 12, 2021 / Published online: May 24, 2021

(c) The Author(s) 2021

\section{ABSTRACT}

Introduction: Despite the continuously growing number of therapeutic options for type 2 diabetes mellitus (T2DM) including insulins, a large percentage of patients fail to achieve HbA1c targets. Several real-world studies focused on patients with T2DM receiving insulin treatment in outpatient settings were conducted, but information about real-world inhospital insulin management is lacking. The aim of this study was to describe the management of insulin therapy with a focus on basalbolus and premixed insulin regimens in

J. Brož $(\bowtie)$ · D. Janíčková Žd'árská · P. Pit’hová .

S. Pálová · B. Pelechová · M. Kvapil

Department of Internal Medicine, Second Faculty of

Medicine, Charles University, V Úvalu 84,

15000 Prague, Czech Republic

e-mail: zorb@seznam.cz

\section{J. Urbanová}

Department of Internal Medicine, Third Faculty of Medicine and Faculty Hospital Královské

Vinohrady, Charles University, Prague,

Czech Republic

V. Doničová

Private Department of Diabetology, Internal

Medicine and Metabolism, Kosice, Slovakia

\section{A. Smržová}

Institute of Biostatistics and Analyses, Ltd., Brno,

Czech Republic patients with T2DM under routine in-hospital medical practice in the Czech Republic.

Methods: This non-interventional prospective study was conducted from June 2014 to December 2017 in 22 centers in the Czech Republic under routine clinical practice conditions. Adult patients admitted to hospital with metabolically uncontrolled T2DM $[\mathrm{HbA} 1 \mathrm{c} \geq 60 \mathrm{mmol} / \mathrm{mol} ;>7.6 \%$ Diabetes Control and Complications Trial (DCCT)] and there treated with basal-bolus and premixed insulin regimens were documented during hospitalization.

Results: Overall, 369 patients with T2DM $(54.7 \%$ male, mean age $64.44 \pm 13.84$ years, BMI $31.10 \pm 6.00 \mathrm{~kg} / \mathrm{m}^{2}$, duration of diabetes $8.11 \pm 9.93$ years,

HbA1c $95.90 \pm 24.38 \mathrm{mmol} / \mathrm{mol}$, length of stay was $7.94 \pm 4.53$ days) were included. The percentage of glucose values under $10 \mathrm{mmol} / \mathrm{l}$ at time of randomization (the group with basal-bolus insulin regimen vs. the premix insulin regimen group) was $24.2 \%$ vs. $33.5 \%(p=0.053)$, at time of first insulin dose adjustment it was $43.1 \%$ vs. $50.0 \%(p=0.330)$, and 1 day before hospital discharge it was $61.7 \%$ vs. $61.4 \%$ $(p=0.107)$. A hypoglycemic event occurred in a total of 15 patients in the basal-bolus regimen group, and no hypoglycemic event occurred in the premixed insulin regimen group.

Conclusion: In-hospital insulin management regarding basal-bolus and premixed insulin 
regimens is safe and in concordance with current international recommendations.

Keywords: Basal-bolus regimen; HbA1c; Hospital insulin management; Hypoglycemia; Insulin titration; Premixed insulin regimen; Type 2 diabetes

\section{Key Summary Points}

The mean HbA1c level at admission was $95.90 \pm 24.38 \mathrm{mmol} / \mathrm{mol}$.

The percentage of glucose values under 10 $\mathrm{mmol} / \mathrm{l}$ at time of randomization (the group with basal-bolus insulin regimen vs. the premix insulin regimen group) was $24.2 \%$ vs. $33.5 \%$.

The percentage of glucose values under 10 $\mathrm{mmol} / \mathrm{l}$ at 1 day before hospital discharge was $61.7 \%$ vs. $61.4 \%$.

\section{DIGITAL FEATURES}

This article is published with digital features, including a summary slide, to facilitate understanding of the article. To view digital features for this article go to https://doi.org/10.6084/ m9.figshare.14573328.

\section{INTRODUCTION}

Despite the new types of antidiabetic drugs, many patients with type 2 diabetes mellitus (T2DM) do not achieve the recommended HbA1c levels [ $<53 \mathrm{mmol} / \mathrm{mol} ; 7 \%$ Diabetes Control and Complications Trial (DCCT)] [1, 2] even with insulin therapy. A Czech cross-sectional study focused on patients with T2DM regardless of the type of treatment they were receiving showed that $34.2 \%$ reached $\mathrm{A} 1 \mathrm{c}<7 \%$ [53 mmol/mol] [3]. A further Czech-Slovak cross-sectional observational study focused on insulin treatment found the portion of patients with well-controlled T2DM $\quad(\mathrm{A} 1 \mathrm{c}<7 \%$ [53 mmol/mol]) to be $33.4 \%$ [4].

Several real-world studies focused on patients with T2DM receiving insulin treatment in outpatient settings were conducted [5], but information about real-world in-hospital insulin management is lacking.

This study was conducted with the aim of describing the management of insulin therapy with a focus on basal-bolus and premixed insulin regimens in patients with T2DM under routine in-hospital medical practice in the Czech Republic.

\section{METHODS}

\section{Study Design}

This is a non-interventional prospective study describing habits associated with certain types of insulin therapy in patients with T2DM admitted to hospital because of insufficiently controlled diabetes in the Czech Republic. The study was conducted from June 2014 to December 2017 and enrolled patients from 22 study centers in the Czech Republic across all regions in the Czech Republic to ensure the highest possible representativeness of the sample. Patients were enrolled onto the study consecutively, with the maximum number of patients per center set at 15 , minimum 5 .

\section{Study Population}

The inclusion criteria were T2DM, patient age of over 18 years with insufficient control of diabetes (HbA1c $\geq 60 \mathrm{mmol} / \mathrm{mol} ;>7.6 \%$ DCCT), who were admitted to the hospital in noncritical conditions and there treated with basal-bolus or premixed insulin regimen therapy which was continued after discharge from hospital. These two types of insulin regimen determined the two study groups.

The exclusion criteria were types of diabetes other than T2DM, hyperglycemia without a previous diagnosis of diabetes, acute hyperglycemic emergencies, or severe hyperglycemia treated with intravenous insulin infusion on 
hospital admission, corticosteroid therapy, and pregnancy, and patients expected to require intensive care unit (ICU) or a hospital stay of shorter than 3 days. In addition, we excluded patients who received parenteral nutrition during the hospitalization.

\section{Insulins Involved in the Study}

None of the insulins available in the Czech Republic during the study period were excluded. The basal insulins included an intermediate-acting insulin (neutral protamine Hagedorn, $\mathrm{NPH}$ ) and long-acting insulin analogues (glargine $100 \mathrm{U} / \mathrm{ml}$, detemir, and in the Slovak Republic also deglutec). The short-acting insulin was recombinant human insulin, and fastacting insulins included insulin analogues (aspart, glulisin, and lispro). Premixed insulin preparations were the proportionate mixtures of a short- or fast-acting insulin and intermediateacting insulins (in proportions of 25/75, 30/70 and 50/50) produced commercially by Eli Lilly, Novo Nordisk, or Sanofi.

\section{Outcomes}

The primary objective of the study was to determine the proportion of patients with basalbolus and premix insulin regimen used in hospitals and the level of glycemia reached at time of discharge.

The secondary objectives were to determine the efficacy of insulin titration (mean change of plasma glucose level) and its comparison between these two insulin regimens, as well as the proportion of patients experiencing hypoglycemic events during hospitalization.

\section{Data Collection}

Data were collected at the inclusion visit (visit 1, day after the admission) and at routine follow-up visits, visit 2 (day of the first insulin dose change) and visit 3 (day before hospital discharge), respectively. Study diabetologists documented data about each patient on a case report form (CRF). During the first visit (V1), insulin therapy was initiated or adjusted, basic anamnestic data was recorded, and physical examination and blood sampling were performed to analyze basic patient parameters including HbA1c.

During the second visit (V2), the dose of insulin currently used by the patient was recorded and, if necessary, adjusted according to the glycemia records. The third visit (V3) followed the same procedure as V2.

\section{Glucose Monitoring}

Glucose monitoring was performed by health staff according to the routine practice of the clinic. Various glucometers were used according to the local customs but all glucometers met the ISO 15197:2013 standards.

\section{Statistical Methods}

Statistical methods commonly used for analysis of epidemiological data were used. All collected information was summarized by descriptive statistics (mean \pm standard deviation/relative frequency). The differences between regimens were tested by the Mann-Whitney-Wilcoxon test in the case of continuous variables and by the Fisher's exact test for discrete variables.

The trend of glycemic profile between 3 days of hospitalization was evaluated with the use of the mixed-effects model based on the method of maximum likelihood estimation. The different days represent the fixed effect, and the particular patient signifies the random effect. The $p$ value displayed in the last column comes from the likelihood ratio test.

\section{Study Interventions}

The study was non-interventional.

\section{Compliance with Ethics Guidelines}

Ethics committee approval was not required for the study as the study was based on collection of anonymous unidentifiable data and did not qualify as a clinical trial of a medicinal product. Under local Czech legislation [6], an ethics committee approval is required only for clinical 
trials of medicinal products. For other types of biomedical research, ethics committee approval is optional. The study was conducted in accordance with the Declaration of Helsinki and informed consent to participate was obtained from all study participants.

\section{RESULTS}

\section{Study Sample}

A total of 389 patients with T2DM were enrolled onto the study, the final eligible population consisting of 369 patients (54.7\% male). The mean age was $64.44 \pm 13.84$ years, with a mean duration of diabetes $8.11 \pm 9.93$ years. The mean length of stay was $7.94 \pm 4.53$ days. An overview of patient group characteristics is shown in Table 1.

The most common reason for admission was insufficient metabolic control of diabetes which was declared in $81.8 \%$ of all patients. Hypoglycemia was a reason for admission in $2.4 \%$ of all the study subjects; the reasons for admission of the rest of the patients are unknown.

At admission, 147 of the patients were treated with basal-bolus insulin regimen, 33 patients with premixed insulin regimen (two insulin shots per day), and the remaining 189 were treated with oral antidiabetic drugs.

During hospitalization 331 patients were treated with basal-bolus insulin regimen, and 38 patients were treated with premix insulin regimen.

\section{Bedside Blood Glucose Monitoring}

The mean daily number of glucose measurements (before breakfast, lunch, dinner and at bedtime) was 3.8 (with additional mean of 0.6 daily measurements $2 \mathrm{~h}$ after breakfast) in the group with basal-bolus insulin regimen and 3.9 (with additional daily mean of 0.4 measurements $2 \mathrm{~h}$ after breakfast) in the group with premixed insulin regimen. Only a small number of measurements were performed in post-lunch, post-dinner periods and during nights; these were not entered into the analysis. The precise distribution of the glucose measurements is shown in Fig. 1.

\section{Glycemic Control}

The mean HbA1c among the whole study group was $95.9 \pm 24.38 \mathrm{mmol} / \mathrm{mol}, \quad 96.1 \pm 24.58$ $\mathrm{mmol} / \mathrm{mol}$ in the group with basal-bolus insulin regimen, and $94.16 \pm 23.44 \mathrm{mmol} / \mathrm{mol}$ in the premix insulin regimen group. Glycemia at admission in the whole group was $17.35 \pm 8.50 \mathrm{mmol} / \mathrm{l}, \quad 17.45 \pm 8.53$ in the group with basal-bolus insulin regimen, and $16.52 \pm 8.24 \mathrm{mmol} / \mathrm{l}$ in the premix insulin regimen group (Table 1 ).

Fasting glycemia at V1 in the group with basal-bolus insulin regimen was $12.19 \mathrm{mmol} / \mathrm{l}$ and $11.05 \mathrm{mmol} / \mathrm{l}$ in the premix insulin regimen group. The analysis of the glycemic difference during insulin titration in V1-3 is shown in Table 2.

The daily average glycemia (SD) at V1 (the group with basal-bolus insulin regimen vs. the premix insulin regimen group) was 13.05 (2.87) vs. $12.18(3.23) \mathrm{mmol} / \mathrm{l}(p=0.058)$; at V2 it was $11.06(2.37)$ vs. $10.73(2.81) \mathrm{mmol} / \mathrm{l}(p=0.171)$; and at V3, it was $9.59(2.13)$ vs. 9.64 (1.88) $\mathrm{mmol} / \mathrm{l}(p=0.695)$ (Table 3). The percentage of measurements with glycemia under $10 \mathrm{mmol} / \mathrm{l}$ did not differ significantly at any visit (Table 3).

\section{Average Insulin Doses and Weight Change During the Study}

The mean daily insulin dose at V1 and V3 (V1/ V3) was $0.50 \pm 0.20 / 0.64 \pm 0.25 \mathrm{U} / \mathrm{kg}$ in the basal-bolus insulin regimen group, and $0.24 \pm 0.15 / 0.44 \pm 0.18 \mathrm{U} / \mathrm{kg}$ in the premix insulin regimen group.

\section{Incidence of Hypoglycemia During the Study}

The frequency of hypoglycemia [number of events/number of measurements (\%)] was 
Table 1 Patient characteristics at V1

\begin{tabular}{llllr}
\hline Type of diabetes & Basal-bolus regimen & Premix regimen & All patients & $\boldsymbol{p}$ value \\
\hline$N$ & 331 & 38 & 369 & \\
Sex & & & & 0.009 \\
Male & $189(57.1 \%)$ & $13(34.2)$ & $202(54.7 \%)$ & \\
Female & $142(42.9 \%)$ & $25(65.8 \%)$ & $167(45.3 \%)$ & \\
Demography and physical measurements & & & \\
Age (years) & $62.74(13.26)$ & $79.32(9.17)$ & $64.44(13.84)$ & $<0.001$ \\
Weight (kg) & $91.00(18.76)$ & $80.42(20.77)$ & $89.92(19.21)$ & $<0.001$ \\
BMI (kg/m $\left.{ }^{2}\right)$ & $31.27(5.90)$ & $29.54(6.77)$ & $31.10(6.00)$ & 0.038 \\
Systolic BP (mmHg) & $139.31(20.17)$ & $139.00(23.29)$ & $139.28(20.48)$ & 0.413 \\
Diastolic BP (mmHg) & $82.22(10.86)$ & $81.54(11.57)$ & $82.15(10.92)$ & 0.809 \\
Diabetic medical history & & & & \\
Duration of DM (years) & $7.62(9.65)$ & $12.45(11.33)$ & $8.11(9.93)$ & 0.003 \\
Laboratory variables & & & & \\
HbAlc (mmol/mol) & $96.10(24.58)$ & $94.16(23.44)$ & $95.9(24.38)$ & 0.441 \\
Glycemia at admission (mmol/l) & $17.45(8.53)$ & $16.52(8.24)$ & $17.35(8.50)$ & 0.435
\end{tabular}

Therapy (percentage of patients)

Long-acting insulin analogues

96.1

Insulin NPH

3.9

Short-acting insulin analogues

95.5

Short-acting human insulin

4.5

Premixed insulin analogues

68.4

Premixed human insulins

31.6

Insulin dose ( $\mathrm{U} / \mathrm{kg} /$ day)

Visit 1

$$
\begin{aligned}
& 0.50 \pm 0.20 \\
& 0.64 \pm 0.25 \\
& 7.75 \pm 4.51
\end{aligned}
$$$$
0.24 \pm 0.15
$$$$
<0.001
$$

Visit 3

$0.44 \pm 0.18$

$<0.001$

Length of stay (days)

$9.51 \pm 4.45$

$7.94 \pm 4.53$

$<0.001$

$18 / 4198(0.4 \%)$ in the basal-bolus regimen group (all of them occurred in a total of 15 patients). Among all cases, 8/977 (0.8\%) were found before breakfast, $0 / 586(0 \%) 2 \mathrm{~h}$ after breakfast, 1/975 (0.1\%) before lunch, 6/959 $(0.6 \%)$ before dinner, and 3/901 (0.3\%) at bedtime. No hypoglycemic event was classified as serious. No hypoglycemic event out of 491 measurements occurred in the premixed insulin regimen group.

\section{DISCUSSION}

This is the first observational real-life study comparing the efficacy and safety of a basal- 
Basal-bolus regimen

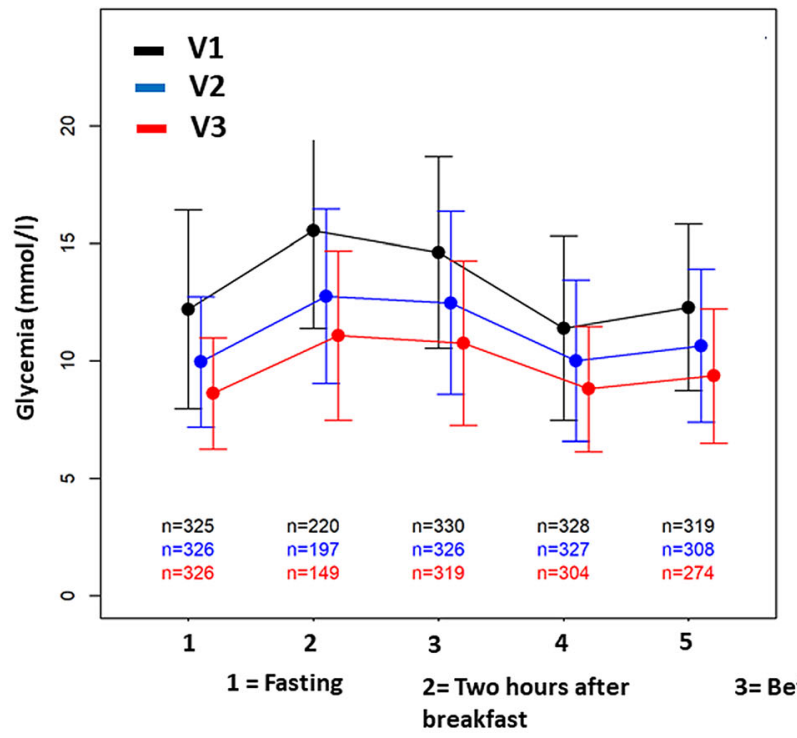

Premixed insulin regimen

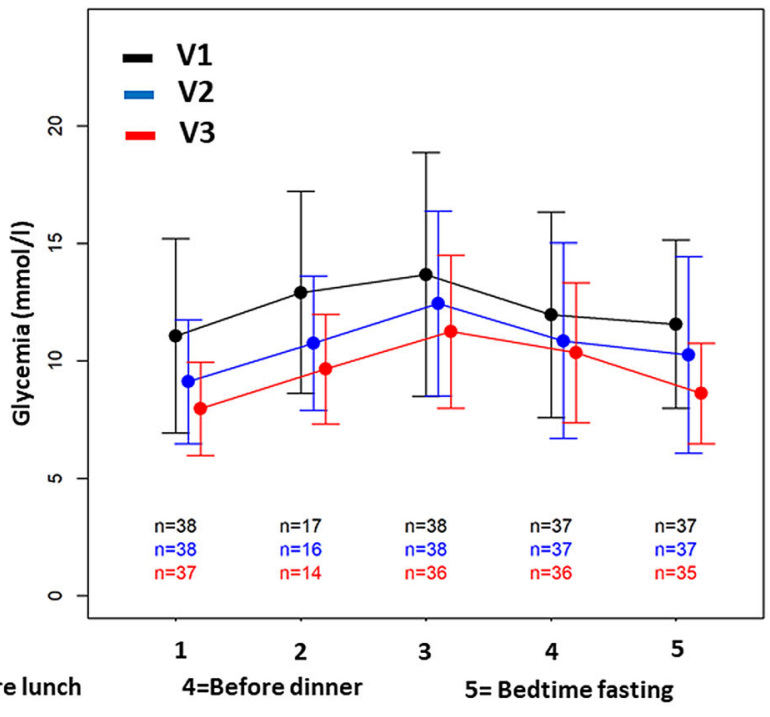

Fig. 1 Mean glycemia levels at different time points (visits 1-3)

bolus insulin regimen with a premixed human insulin regimen in hospitalized patients with type 2 diabetes. Both treatment regimens resulted in a significant improvement in the mean daily blood glucose concentration and in the percentage of glucose readings within the target range of 80 and $180 \mathrm{mg} / \mathrm{dl}$ before meals; the mean daily glycemia did not differ between both regimen groups.

The aim of the study was to determine the manner in which insulin therapy was conducted among metabolically uncontrolled patients with T2DM admitted to a hospital in noncritical condition. The majority of patients were referred to a hospital by their diabetologists for insulin initiation or insulin therapy adjustment. At the time of hospital discharge, the majority of patients were treated with basalbolus insulin regimen and the rest of them with premixed insulin regimen. The most prevalent choice of insulin regimen is concordant with the current recommendation for in-hospital insulin treatment of patients with uncontrolled T2DM under noncritical conditions [7]. Although the premixed insulin regimen is not recommended for in-hospital settings as it was found to be linked to frequent hypoglycemic episodes [8], up to $10 \%$ of patients were treated with this type of insulin management. The majority of them had been treated with a premixed regimen during their pre-hospital period, but 12 patients started with this type of therapy during their hospitalization.

The precise reasons for the therapy regimen choice were not ascertained in the study, but patients treated with a pre-mixed regimen were much older, with an average age of almost 80 years. However, their mean HbA1c level was similar to that in the basal-bolus group. Thus, we may speculate that the regimen choice was caused by the inability of the patients to properly carry out daily multiple insulin dose therapy, or that they required assistance with insulin injections which sometimes was not possible to arrange for nighttime injections at homecare settings, as previously described [9-11]. The length of stay was significantly longer in the pre-mixed regimen group, which might be explained by the longer period of time necessary for insulin dose adjustment.

The bedside glucose monitoring frequency correlated with the recommendations [12] and was performed on average before almost every meal and at bedtime in both groups. Additional tests were quite frequently performed $2 \mathrm{~h}$ after breakfast. 
Table 2 Differences in glycemia at V1-3 in the basal-bolus a premixed insulin regimen groups

\begin{tabular}{|c|c|c|c|c|}
\hline & $\begin{array}{l}\text { Basal-bolus } \\
\text { regimen }(\mathbf{m m o l} / \mathbf{l})\end{array}$ & $p$ value* & $\begin{array}{l}\text { Premixed insulin } \\
\text { regimen }(\mathbf{m m o l} / \mathbf{l})\end{array}$ & $p$ value ${ }^{*}$ \\
\hline \multicolumn{5}{|l|}{ Fasting } \\
\hline Visit 1 & 12.19 & & 11.05 & \\
\hline Visit 2 & -2.26 & & -1.94 & \\
\hline Visit 3 & -3.58 & $<0.001$ & -3.11 & $<0.001$ \\
\hline \multicolumn{5}{|c|}{ Two hours after breakfast } \\
\hline Visit 1 & 15.54 & & 12.91 & \\
\hline Visit 2 & -2.7 & & -2.18 & \\
\hline Visit 3 & -4.69 & $<0.001$ & -3.31 & 0.016 \\
\hline \multicolumn{5}{|c|}{ Before lunch } \\
\hline Visit 1 & 14.61 & & 13.67 & \\
\hline Visit 2 & -2.16 & & -1.23 & \\
\hline Visit 3 & -3.88 & $<0.001$ & -2.5 & 0.002 \\
\hline \multicolumn{5}{|c|}{ Before dinner } \\
\hline Visit 1 & 11.38 & & 11.95 & \\
\hline Visit 2 & -1.4 & & -1.11 & \\
\hline Visit 3 & -2.63 & $<0.001$ & -1.67 & 0.055 \\
\hline \multicolumn{5}{|l|}{ Bedtime } \\
\hline Visit 1 & 12.28 & & 11.56 & \\
\hline Visit 2 & -1.65 & & -1.3 & \\
\hline Visit 3 & -2.98 & $<0.001$ & -2.96 & $<0.001$ \\
\hline
\end{tabular}

${ }^{*}$ Likehood ratio test

Both treatment regimens resulted in a significant improvement in the pre-meal and postbreakfast glucose concentration (the difference before dinner in the pre-mixed regimen was on the borderline of statistical significance) and in a similar percentage of glucose readings within the target range of below $10.0 \mathrm{mmol}(180 \mathrm{mg} /$ dl). Similar results were found in the study by Bellido et al. [8].

Interestingly, a very small amount of hypoglycemia occurred during the treatment, and even more interestingly, all the events were found in the basal-bolus regimen group. This sharply contrasts with the findings of Bellido et al., whose study was stopped early because the frequency of hypoglycemia was greater than $50 \%$ in patients treated with the premixed human insulin regimen, while it was only onethird in the basal-bolus group. We believe that the main reason for such a difference was the glycemic target for every insulin dose in the previously mentioned study. According to protocol, every dose of insulin should be adjusted for a glycemic target of between 7.8 and $10 \mathrm{mmol} / \mathrm{l}$ before meals. There was no such target in our study, so insulin dosing changes could be more finely tuned, thereby avoiding the higher frequency of hypoglycemia. Also in our study the glycemic values were higher at the beginning of insulin adjustment, which also 
Table 3 Changes in mean daily blood glucose concentration and percentage of measurements with glycemic values $<10 \mathrm{mmol} / 1$

\begin{tabular}{|c|c|c|c|c|c|c|}
\hline & \multicolumn{3}{|c|}{ The mean daily glycemia $(\mathrm{mmol} / \mathrm{l})$} & \multicolumn{3}{|c|}{$\begin{array}{l}\text { The percentage of measurements with glycemia } \\
\text { under } 10 \mathrm{mmol} / 1(\%)\end{array}$} \\
\hline & $\begin{array}{l}\text { Basal-bolus } \\
\text { regimen }(\mathrm{mmol} / \mathrm{l})\end{array}$ & $\begin{array}{l}\text { Premixed insulin } \\
\text { regimen }(\mathrm{mmol} / \mathrm{l})\end{array}$ & $\overline{p \text { value }}$ & $\begin{array}{l}\text { Basal-bolus } \\
\text { regimen }(\mathrm{mmol} / \mathrm{l})\end{array}$ & $\begin{array}{l}\text { Premixed insulin } \\
\text { regimen }(\mathrm{mmol} / \mathrm{l})\end{array}$ & $\overline{p \text { value }}$ \\
\hline $\begin{array}{c}\text { Visit } \\
1\end{array}$ & $13.05(2.87)$ & $12.18(3.23)$ & 0.058 & 24.2 & 33.5 & 0.053 \\
\hline $\begin{array}{c}\text { Visit } \\
2\end{array}$ & $11.06(2.37)$ & $10.73(2.81)$ & 0.171 & 43.1 & 50.0 & 0.330 \\
\hline $\begin{array}{c}\text { Visit } \\
3\end{array}$ & $9.59(2.13)$ & $9.64(1.88)$ & 0.695 & 61.7 & 61.4 & 0.107 \\
\hline
\end{tabular}

might contribute to the low frequency of hypoglycemia. Another possible explanation might be that a substantially high proportion of our patients was treated with premixed insulin analogues linked to a lower frequency of hypoglycemia, contrary to the study by Bellido et al. [8] in which only premixed human insulin was used.

There is a significant difference between the mean insulin doses at the time of insulin initiation and at the time of discharge; the insulin dose in the premixed regimen is lower. This could be explained by concomitant oral antidiabetic therapy, but unfortunately such information is not available. Also, it should be noted that patients in the premixed regimen are older with slightly lower glycemia at admission. Both these characteristic might lead physicians to safer insulin dosing at the time of insulin introduction.

We acknowledge several limitations in the study. The patients with basal insulin only regimen were not entered into the study protocol as this type of insulin initiation is usually provided in outpatient units.

The number of patients in the premixed regimen group is relatively small but the relation between both regimen groups reflects usual daily hospital practice. Also it should be mentioned that certain groups of patients, mainly those in critical conditions (see exclusion criteria), were not included in the study. Some patient information was missing, such as therapy with oral antidiabetic drugs and comorbidities. Unfortunately, we were not able to collect these data in the all patients.

In addition, we lack information on nutritional intake and missed meals, which represents a significant risk factor for hypoglycemia and overall glycemic control in the hospital setting.

Nevertheless, we believe that, our study is the only observational study focused on inhospital insulin management in patients admitted to the hospital in noncritical conditions and there treated with basal-bolus or premixed insulin regimen therapy which was continued after discharge from hospital and that the presented results show important information about routine clinical practice in the Czech hospitals related to this type of therapy.

\section{CONCLUSIONS}

In-hospital insulin management regarding basal-bolus and premixed insulin regimens is safe and in concordance with current international recommendations. 


\section{ACKNOWLEDGEMENTS}

We thank the study participants.

Funding. This study and the journal's Rapid Service Fee were funded by the Diabetes Association of the Czech Republic. The role of the sponsor was to appoint an independent research company for the statistical analysis and carry out the study (Institute of Biostatistics and Analyses, Ltd.). All authors had full access to all of the data in this study and take complete responsibility for the integrity of the data and accuracy of the data analysis.

Editorial Assistance. Special thanks to Dion Pritchard for language editing. Article language editing was funded by the Diabetes Association of the Czech Republic.

Authorship. All named authors meet the International Committee of Medical Journal Editors (ICMJE) criteria for authorship for this article, take responsibility for the integrity of the work as a whole, and have given their approval for this version to be published.

Authors' Contributions. J.B. initiated the study and contributed to the study design, data analysis and interpretation, as well as the drafting, review, and editing of the manuscript, and in doing so led all of the efforts. D.J.Z., J.U, V.D, and B.P. contributed to the study design, data analysis and interpretation, as well as the drafting, review, and editing of the manuscript. A.S. contributed to the data analysis, drafting of the manuscript, and the review and editing of the manuscript. M.K. is a guarantor of this work and, as such, had full access to all the data in the study and takes responsibility for the integrity of the data and the accuracy of the data analysis. All named authors meet the International Committee of Medical Journal Editors (ICMJE) criteria for authorship for this article, take responsibility for the integrity of the work as a whole, and have given their approval for this version to be published.

Disclosures. Jan Brož, Denisa Janíčková Žd'árská, Jana Urbanová, Pavlína Pit'hová, Viera
Doničová, Sabina Pálová, Barbora Pelechová, Anna Smržová and Milan Kvapil declare no potential conflicts of interest.

Compliance with Ethics Guidelines. Ethics committee approval was not required for the study as the study was based on collection of anonymous unidentifiable data and did not qualify as a clinical trial of a medicinal product. Under local legislation Czech Pharmaceuticals Act No. 378/2007 Sb., an ethics committee approval is required only for clinical trials of medicinal products. For other types of biomedical research, ethics committee approval is optional. The study was conducted in accordance with the Declaration of Helsinki and informed consent to participate was obtained from all study participants.

Data Availability. The data sets generated during and/or analyzed during the current study are available from the corresponding author on reasonable request.

Open Access. This article is licensed under a Creative Commons Attribution-NonCommercial 4.0 International License, which permits any non-commercial use, sharing, adaptation, distribution and reproduction in any medium or format, as long as you give appropriate credit to the original author(s) and the source, provide a link to the Creative Commons licence, and indicate if changes were made. The images or other third party material in this article are included in the article's Creative Commons licence, unless indicated otherwise in a credit line to the material. If material is not included in the article's Creative Commons licence and your intended use is not permitted by statutory regulation or exceeds the permitted use, you will need to obtain permission directly from the copyright holder. To view a copy of this licence, visit http://creativecommons.org/licenses/by$\mathrm{nc} / 4.0 /$. 


\section{REFERENCES}

1. Selvin E, Parrinello ChM, Daya N, Bergenstal RM. Trends in insulin use and diabetes control in the $\mathrm{U}$. S.: 1988-1994 and 1999-2012. Diabetes Care. 2016;39(3):e33-5. https://doi.org/10.2337/dc152229.

2. Pablos-Velasco P, Parhofer KG, Bradley C, et al. Current level of glycaemic control and its associated factors in patients with type 2 diabetes across Europe: data from the PANORAMA study. Clin Endocrinol. 2014;80:47-56.

3. Zdarska DJ, Hill M, Kvapil M, Pithova P, Broz J. Analysis of postprandial glycemia in relation to metabolic compensation and other observed parameters of outpatients with type 2 diabetes mellitus in the Czech Republic. Diabetes Ther. 2018;9:665-72.

4. Brož J, Janíčková Žd'árská D, Urbanová J, et al. Current level of glycemic control and clinical inertia in subjects using insulin for the treatment of type 1 and type 2 diabetes in the Czech Republic and the Slovak Republic: results of a multinational, multicenter, observational survey (DIAINFORM). Diabetes Ther. 2018;9:1897. https://doi.org/10. 1007/s13300-018-0485-2.

5. Brož J, Janíčková Ždárská D, Urbanová J. Results of insulin therapy in type 2 diabetes mellitus patients in the Czech Republic: do they reflect the current status in other countries? Diabetes Ther. 2019;10(4):1181-8. https://doi.org/10.1007/
6. Czech Pharmaceuticals Act No. 378/2007 Sb. https://www.sukl.eu/sukl/pursuant-to-act-no-378-

2007-coll-on-pharmaceuticals-and-on. Accessed 23 Nov 2020.

7. American Diabetes Association. Diabetes care in the hospital: standards of medical care in diabetes2019. Diabetes Care. 2020;43(suppl 1):S193-202.

8. Bellido V, Suarez L, Rodriguez MG, et al. Comparison of basal-bolus and premixed insulin regimens in hospitalized patients with type 2 diabetes. Diabetes Care. 2015;38:2211-6.

9. Schiel R, Muller UA, Rauchfub J, Sprott H, Muller R. Blood-glucose self-monitoring in insulin treated type 2 diabetes mellitus a cross-sectional study with an intervention group. Diabetes Metab. 1999;25: 334-40.

10. Eliasson B, Ekstrom N, Bruce Wirta S, et al. Metabolic effects of Basal or premixed insulin treatment in 5077 insulin-naïve type 2 diabetes patients: registry based observational study in clinical practice. Diabetes Ther. 2014;5:243-54.

11. Kalra S, Balhara YP, Sahay BK, et al. Why is premixed insulin the preferred insulin? Novel answers to a decade-old question. J Assoc Physicians India. 2013;61(Suppl):9-11.

12. Moghissi ES, Korytkowski MT, Di Nardo M, et al. American Association of Clinical Endocrinologists; American Diabetes Association. American Association of Clinical Endocrinologists and American Diabetes Association consensus statement on inpatient glycemic control. Diabetes Care. 2009;32: 1119-31. 